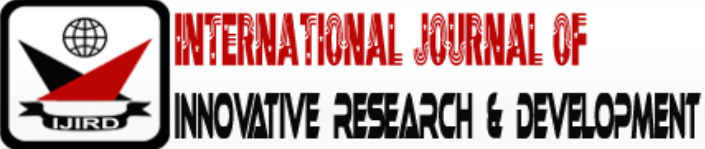

ISSN 2278 - 0211 (Online)

\section{Photocatalytic Degradation of 4-Chlorophenol by Titanium Dioxide: Role of Annealing Temperature and Morphology}

\author{
Dr. Patrick K. Tum \\ Lecturer, Department of Chemistry, University of Nairobi, Kenya \\ David K. Kariuki \\ Associate Professor, Department of Chemistry, University of Nairobi, Kenya
}

\begin{abstract}
:
This work investigates the degradation rate of 4-cholorphenol using photocatalysts. Chlorophenols and their compounds are a nuisance as they are recalcitrant to degradation in the environment. Three morphologically different Titanium dioxide catalysts, A, B and C, were immobilized on microscopic glass at a layer of $0.5 \mathrm{mg} / \mathrm{cm}^{2}$ and annealed between $500-700^{\circ} \mathrm{C}$. The three different $\mathrm{TiO}_{2}$ powders were characterized using Scanning Electron Microscopy, X-Ray Diffraction and Brunauer Emmett Teller to determine their specific surface area, crystalline and particle sizes. A fourposition photocatalytic reactor illuminated by two Ultra violet lamps of wavelength range 320-400 nm and intensity $\mathrm{I}=27.87 \mathrm{~mW} / \mathrm{m}^{2}$ was used to degrade the 4-Chlorophenol in $2 \mathrm{hrs}$. Aliquots of the degraded 4-chlorophenol were drawn every 30 minutes and analyzed using UV-Vis spectroscopy at $\lambda=226 \mathrm{~nm}$. The optimum annealing temperature of all $\mathrm{TiO}_{2}$ was found to be $650^{\circ} \mathrm{C}$, with type $\mathrm{B}$ of hexagonal morphological structure and particle size of $28 \pm 2 \mathrm{~nm}$ having the highest 4-chlorophenol degradation rate, of $71.21 \%$.
\end{abstract}

Keywords: Photocatalytic degradation, 4-chlorophenol, $\mathrm{TiO}_{2}$, annealing temperature, morphology

\section{Introduction}

Chlorinated phenols are categorized as first-degree pollutants due to their persistent toxicity, suspected carcinogenity and mutagenity. Chlorophenols (CPs) in general, when released into the environment poses serious ecological problems to all living organisms (Movahedyan et al., 2008). Among the chlorophenols, 4-chlorophenol has attracted a lot of interest owing to its direct relevance to the environment and its unique photochemical characteristic (Krysa et al., 2006).

Chlorophenols find their way into water systems as a result of discharge from chemical industries, have proved resistant to conventional chemical and biological treatments. Some of the industries from which large volumes of chlorophenols are discharged include; petroleum refining, production of pesticides, paint, plastic, resins, textiles, iron-ore processing, solvent synthesis and pharmaceutical productions (Gomez et al., 2009; Movahedyan et al., 2009; Olaniran and Igbinosa, 2011; Pera-Titus et al., 2004; Pi et al., 2007). As a result of water pollution, the sustainable approach to water sources management should therefore include treatment technologies that reduce the negative effects and promote sustainable use of water resources by facilitating recycling and reusing of wastewater (Catrinescu et al., 2011).

Advanced Oxidation Processes (AOPs) is one such process that constitute a collection of established treatment technologies which depend on the formation of hydroxyl radicals $(\cdot \mathrm{OH})$ that mineralize non-selectively all contaminants into carbon dioxide and water (Assadi \& Eslami, 2010; Gaya et al., 2009; Dan et al., 2004). Researchers have investigated on the removal phenolic compounds using several techniques that include; Ultra-violet/ $\mathrm{H}_{2} \mathrm{O}_{2}$, Ultra-violet/ catalyst, photoFenton process, MW/ NiO, Ultra-violet/ $\mathrm{H}_{2} \mathrm{O}_{2} / \mathrm{TiO}_{2}, \mathrm{O}_{3} / \mathrm{ZnO}$, Graphite and graphene oxides, Microwave/ Ultra-violet and UV/ $\mathrm{O}_{3} / \mathrm{TiO}_{2}$ (Marianna, 2006; Lin et al., 2008; Ghaly et al., 2001; Kuo and Lin, 2009; Lai et al., 2007; Chiou et al., 2007; Dixit et al., 2010; Tabatabaei et al., 2011; Bustos-Ramirez et al., 2015; Seo et al., 2017; Gimeno et al., 2005). In addition, the use of microbial cultures Alcaligenes in a fermenter has been reported by (Westmeier and Rehm, 1987) to remove 4Chlorophenol in wastewater. These methods have largely not been very effective and there is need for further research for the effective and economical removal of 4-Chlorophenol from wastewater. This work investigates the role of annealition temperature in the $\mathrm{UV} / \mathrm{TiO}_{2}$ treatment system to degrade 4-Chlorophenol in wastewater. This work anticipates that the optimization of Titanium dioxide's mechanical and chemical properties as well as illumination with ultraviolet light improves the catalytic activity, hence the degradation rate of 4-Chlorophenol. At annealing temperatures of $500-700^{\circ} \mathrm{C}$, $\mathrm{TiO}_{2}$ morphology transforms from anatase to rutile phase, thereby improving its photocatalytic activity. Anatase $\mathrm{TiO}_{2}$ is mostly used for environmental management, such as water purification, wastewater treatment and water disinfections (Carp et al., 2004; Eslami et al., 2007). It is biologically and chemically inert, stable with respect to photo and chemical corrosion, low cost, active over a wide range of $\mathrm{pH}$, high refractive index, efficient and long-term stability (Ghosh et al., 2009). A draw-back in the application of $\mathrm{TiO}_{2}$ is its high band gap energy of $3.2 \mathrm{e} . \mathrm{V}$, that allows titanium dioxide to absorb 
only UV light of wavelength lower than $388 \mathrm{~nm}$ thereby reducing solar light harvesting efficiency down to 5\% (Ajmal et al., 2014; Gaya et al., 2009; Barnes et al., 2010). Anatase also has a low mineralization level that is acquired when on largescale applications and therefore requires a final polishing stage (Gimeno et al., 2004). These shortcomings have renewed efforts to research on reliable and more effective catalysts (Catrinescu et al., 2011; Li et al., 2009). Photocatalytic oxidation processes are related to catalytically active metal oxides such as $\mathrm{ZnO}, \mathrm{TiO}_{2}$, and $\mathrm{ZrO}_{2}$ which are semiconductors and remove contaminants in wastewater (Lo et al., 2004). They are mainly the oxides of transition metals (Lai et al., 2008; Stoyanova and Christoskova, 2011; Stoyanova et al., 2003). The equations below indicate the reactions that take place when $\mathrm{TiO}_{2}$ reacts as a semi-conductor.

$$
\begin{aligned}
& \mathrm{TiO}_{2}+\mathrm{hv} \rightarrow \mathrm{e}_{\mathrm{CB}}^{-}+\mathrm{h}_{\mathrm{VB}}^{+} \\
& \mathrm{O}_{2}+\mathrm{e}_{\mathrm{CB}}^{-} \rightarrow \mathrm{O}_{2}^{--} \\
& \mathrm{H}_{2} \mathrm{O}+\mathrm{h}_{\mathrm{VB}}^{+} \rightarrow \mathrm{OH}^{-}+\mathrm{H}^{+}
\end{aligned}
$$

The contaminant in this study, 4-Chlorophenol contains pesticide properties. It is a characteristic faint yellow liquid with an unpleasant, penetrating odour, molecular mass $\mathrm{M}_{\mathrm{r}}=128.56 \mathrm{~g}^{\mathrm{mol}}{ }^{-1}$ with a chemical formula $\mathrm{C}_{6} \mathrm{H}_{5} \mathrm{OCl}$. The structural formula of 4-Chlorophenol is shown in figure 1 below.

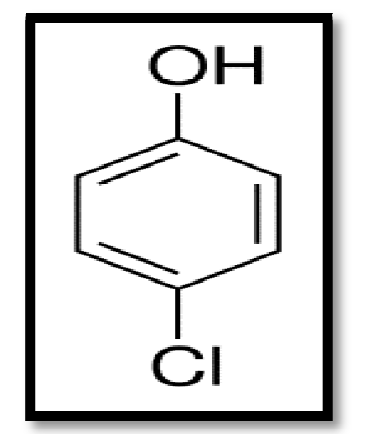

Figure 1: 4-Chlorophenol

\section{Materials and Methods}

\subsection{Chemicals}

Three different types of Titanium dioxide powder were sourced from Sigma-Aldrich and identified as A, B \& C. Lanthanum hexaboride and 4-Chlorophenol of purity 99\% was also obtained from Sigma - Aldrich.

\subsection{Equipment}

UV/Vis spectrophotometer model 4000 from Shimadzu Ltd, UV light intensity meter, X-ray diffractometer and Scanning Electron Microscope model Tescan VEGA3 equipment were used

\subsection{Methods}

Morphological Characterization of $\mathrm{TiO}_{2}$ powder catalysts using Scanning Electron Microscopy, X-Ray diffraction and Brunauer Emmett-Teller procedures are explained here below.

\subsubsection{Scanning Electron Microscopy (SEM) - Crystal size}

A Tescan VEGA3 Scanning Electron Microscope equipped with a field emission source was preferred over regular SEM with Lanthanum hexaboride filament as a high voltage source for morphological characterization. This is because of its high resolution and brightness at low accelerating voltages that allows for clearer images. Prior to SEM, the samples were first mounted on an aluminum stub using a double-sided carbon tape, and then coated with a thin layer of 10-30 nm composed of 60:40 gold-palladium alloy by means of vacuum sputtering coating using a Denton Desk 1 Sputter-Coater under a 70 mtorr vacuum. Other conditions included: (SEM HV-20.0 kV, view field- $6.36 \mu \mathrm{m}$ and SEM mag $30.0 \mathrm{kx}$ ).

- Two sample of each $\mathrm{TiO}_{2}$ powder were inscribed for identification

- The samples were dried at an oven $60^{\circ} \mathrm{C}$ for 3 hours

- The samples were loaded into the SEM and blown with inert nitrogen gas to protect any further oxidation reactions.

- The acceleration voltage was set at $20 \mathrm{KV}$, lowest magnification (30X) and TV mode.

- The coarse focus was switched on and the focus knob adjusted to a safe working distance of $14 \mathrm{~mm}$.

- The focus was switched to slow scan mode and magnification increased. The samples stage was brought up slowly by pressing z-axis UP key. The variable button was opened up to open a small variable window on the screen. The image was focused within the small screen using outer focus ring and inner focus ring until indicator light reaches the middle.

- The image was previewed and adjusted to contrast and the image set-up window closed. The image acquire icon was clicked to record the image formed and the image saved. 


\subsubsection{X-Ray Diffractometer (XRD) - Crystallite Size}

Particle sizes are calculated by XRD using the Scherer's equation $l=k \lambda / \beta \cos \theta$.

$\lambda$ is the wavelength of rays,

$\mathrm{k}$ is a constant taken to be 0,9 (assuming no crystal distortions in the lattice),

$\beta$ is the width at half maximum of the radians corrected for the instrumental broadening and

$\theta$ is the diffraction angle in degrees.

- Scan parameters: start and end 2q limits $0-130$ - 2q

- Step size $0.5-0.1-2 q$

- $\quad$ Step time $(1 \mathrm{sec})$

- Start scan

- When scan was completed the file was saved

\subsubsection{Brunauer Emmett Teller (BET) - Surface Area Analysis}

The BET surface area was measured through a multipoint method utilizing adsorption data in the relative pressure (P/ Po) in the range $0.005-0.3$ using nitrogen (99.99\%) physico-sorption at $200^{\circ} \mathrm{C}$.

- The system used liquid nitrogen in a $500 \mathrm{ml}$ Dewar flask placed on the stage of the instrument.

- $\mathrm{ZnO}$ and $\mathrm{TiO}_{2}$ were heated at $150^{\circ} \mathrm{C}$ for 2 hours to remove adsorbed water

- The resolution of the images formed were set at 80 seconds

\subsubsection{Measurement of Irradiation Intensity}

The irradiation intensity emitted by UV lamps in the four-hole photoreactor was measured using a light intensity meter positioned at a distance of $0 \mathrm{~cm}$ next to the metallic openings from which UV light was irradiated. The light intensity values were measured at the start and end of each experiment and included in the final value of the rate of photocatalytic degradation. The UV light intensity was measured at $\mathrm{I}=27.87 \mathrm{~mW} / \mathrm{m}^{2}$.

UV-Vis spectrophotometric measurements of 4-chlorophenol A stock solution of $0.0001 \mathrm{~mol}_{\mathrm{L}} \mathrm{L}^{-1}$ in a $500 \mathrm{ml}$ round bottomed flask was made and its absorbance measured using a UV-Vis spectrophotometer. An aliquot of $5 \mathrm{ml} \mathrm{4-}$ Chlorophenol was put into the cuvette and placed in the spectrophotometer. A full UV-Vis scan of 4-Chlorophenol sample was carried out at wavelengths between 200- $600 \mathrm{~nm}$ and the spectrum recorded as shown in figure 6 .

\subsubsection{Calibration Curve - 4-Chlorophenol Spectral Analysis Molar Extinction Coefficient (E)}

The coefficient $(\varepsilon)$ is calculated from the Beer Lamberts law shown in (4) below;

$\mathrm{A}=\varepsilon \mathrm{LC}$

Where:

A is the amount of light absorbed by samples at specific wavelengths $(\lambda)$

$\mathrm{E} \quad$ is the molar extinction coefficient

$\mathrm{L} \quad$ is the length of cuvette used to measure absorbance

$\mathrm{C} \quad$ is the concentration of the absorbing sample

To determine the extinction coefficient of 4-chlorophenol $(\varepsilon)$, at $226 \mathrm{~nm}$ concentrations of solutions were prepared; $1 \times 10^{-5} \mathrm{~mol} . \mathrm{L}^{-1}, 2.5 \times 10^{-5} \mathrm{~mol} . \mathrm{L}^{-1}, 5 \times 10^{-5} \mathrm{~mol} . \mathrm{L}^{-1}$ and $1 \times 10^{-4} \mathrm{~mol} . \mathrm{L}^{-1}$. A calibration curve for 4-Chlorophenol using different solution concentrations was obtained and is shown in figure 7 and its molar extinction coefficient calculated.

\subsection{Photocatalytic Degradation of 4-Chlorophenol}

The experimental temperature was set at $23^{\circ} \mathrm{C}$. The four cuvettes were filled with $25 \mathrm{ml}$ of $1 \times 10^{-4} \mathrm{~mol} . \mathrm{L}^{-1}$ of $4-$ chlorophenol and placed against each of the four holes in the photocatalytic reactor before the UV lamps and the magnetic stirrer were switched on. At the start of the experiment, absorbance was measured and the value recorded for each of the $\mathrm{TiO}_{2}$ catalyst layers. The fourth cuvette was the experimental control. The absorbance of the solutions was determined at $\lambda=226 \mathrm{~nm}$ and after every 30 minutes of photocatalytic treatment, $5 \mathrm{ml}$ of the 4-Chlorophenol solution was withdrawn from each cuvette, its absorbance recorded till the $120^{\text {th }}$ minute. The rate of 4-Chlorophenol degradation was considered to cover a geometrical area $0.000875 \mathrm{~m}^{2}$ covered by $\mathrm{TiO}_{2}$ catalyst immobilized on microscopic glass. The rate was calculated as shown by formula (5) and (6) below and expressed as (mol.m-2.W-1).

$r_{A}=\frac{\left(c_{0}-c_{60}\right) V}{t_{60}-t_{0}} \cdot \frac{1}{A}$

$\mathrm{r}_{\mathrm{A}} \quad$ rate of 4-Chlorophenol in degradation $\left(\mathrm{mol} \cdot \mathrm{m}^{-2} \cdot \mathrm{h}^{-1}\right)$

$\mathrm{C}_{o} \quad$ initial 4-Chlorophenol in concentration (mol.L-1)

$\mathrm{C}_{60} \quad$ 4-Chlorophenol concentration after 1 hour $\left(\mathrm{mol}^{\left.-\mathrm{L}^{-1}\right)}\right.$

$\mathrm{t} \quad$ time at which irradiation started ( 0 hours.)

$t_{60} \quad$ time of irradiation (1 hour)

$\mathrm{V} \quad$ volume of 4-Chlorophenol irradiated in cuvette $(0.025 \mathrm{ml})$

A irradiated geometric surface area of particulate film $\left(0.000875 \mathrm{~m}^{2}\right)$

The rate of photodegradation relative to incident UV light intensity is then calculated according to equation 6 below . 
$r_{I}=\frac{r_{A}}{I}$

Where $r_{I}$ the rate of 4-Chlorophenol photocatalytic degradation (mol.h-1. $\left.\mathrm{W}^{-1}\right)$ and $I$ is UV light intensity $\left(\mathrm{mW} / \mathrm{m}^{2}\right)$.

\subsubsection{Preparation of $\mathrm{TiO}_{2}$ Coated Layers Immobilized on Microscopic Glass}

Catalyst suspensions of concentration 10 g.L-1 were prepared from the 3 samples; A, B and C in 100 ml volumetric flasks. The suspensions were further homogenized in an ultrasonic bath for 30 seconds to break-up any agglomerates present. A volume of $3.75 \mathrm{ml}$ of the $\mathrm{TiO}_{2}$ suspensions were taken using a $5 \mathrm{ml}$ syringe and immobilized onto a clean, dry and degreased microscopic glass slides of dimensions $75 \mathrm{~mm}$ x $25 \mathrm{~mm}$ and placed on ceramic tile and allowed to dry at room temperature for 1 hour. The coated layers were then dried at $50^{\circ} \mathrm{C}$ in an oven for 30 minutes to further fixate the catalyst particles onto the glass. The final procedure involved the annealition of the layers attached onto porcelain crucibles in a furnace at 500,550,600,650 \& 650 $\mathrm{C}$ for a duration of 2 hours. The annealed layers were trimmed to reduce the geometric area covered by the catalyst to $0.000875 \mathrm{~m}^{2}$ and loading of $0.5 \mathrm{mg} / \mathrm{cm}^{2}$. The procedure described above was used to prepare particulate layers for all the three catalysts.

\subsubsection{Photocatalytic Degradation Reactor}

The photocatalytic reactor was operated in batch mode and consisted of a magnetic stirrer. Three cuvettes of 30 $\mathrm{ml}$ were placed onto the holes illuminating UV light. The stirring rate was set at 900 rotations/ min. Each of the cuvettes was filled with $25 \mathrm{ml}$ of 4-Chlorophenol $\mathrm{c}\left(1 \times 10^{-4}\right.$ mol.L-1). The photoreactor was attached to a thermostat to regulate its temperature as shown in figure 2 below. The $\mathrm{TiO}_{2}$ coated layers prepared from the procedure described in section (2.4.1) were suspended using metallic clips and dipped into cuvettes containing 4-Chlorophenol solutions. The cuvettes consisting of 4-Chlorophenol solutions and $\mathrm{TiO}_{2}$ coated layers were illuminated with UV light from 2 lamps. The intensity of the UV light was measured by a light intensity meter.

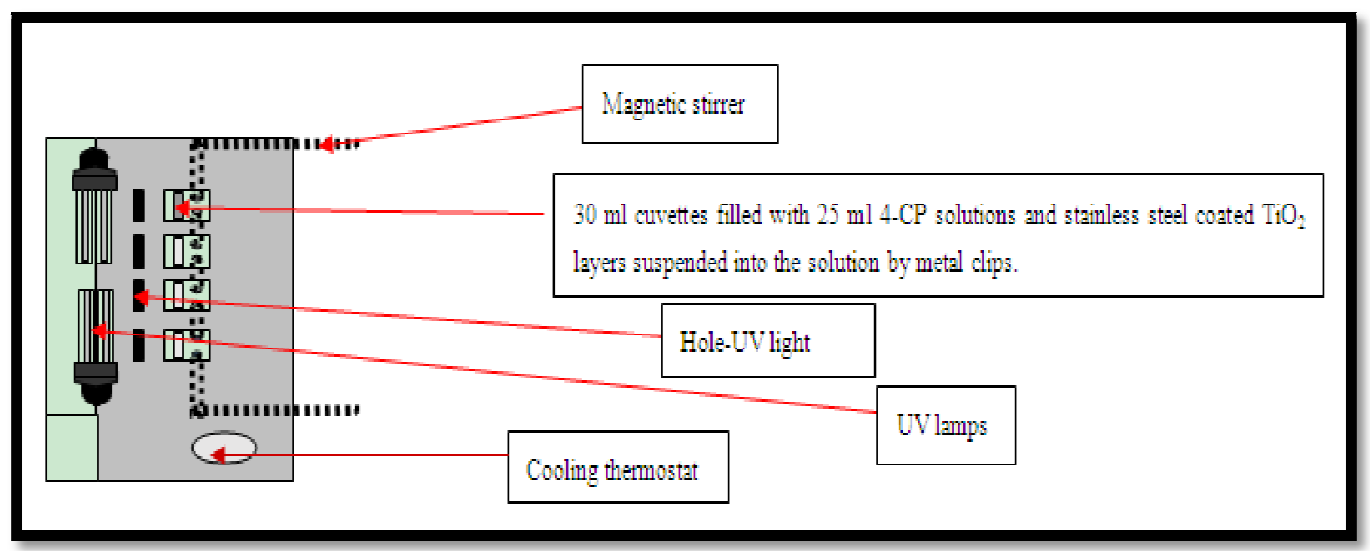

Figure 2: Four-Hole Photocatalytic Reactor

\section{Results and Discussion}

\subsection{Characterization of Tio2 Powder Catalysts}

\begin{tabular}{|c|c|c|c|}
\hline Sample & $\begin{array}{c}\text { Agglomerate Size (Nm) } \\
\text { (SEM) }\end{array}$ & $\begin{array}{c}\text { Crystal Size (Nm) } \\
\text { (XRD) }\end{array}$ & $\begin{array}{c}\text { Specific Surface Area (M²/ G) } \\
\text { (BET) }\end{array}$ \\
\hline A & $200-300$ & 28 & 50 \\
B & 300 & 169 & 10 \\
C & $100-300$ & 9 & 250 \\
\hline
\end{tabular}

Table 1: Morphological Characterization - (XRD, SEM \&BET)

Table 1 and figure 3, 4 and 5 presents the results from the morphological characterization of the catalysts used in this study. 


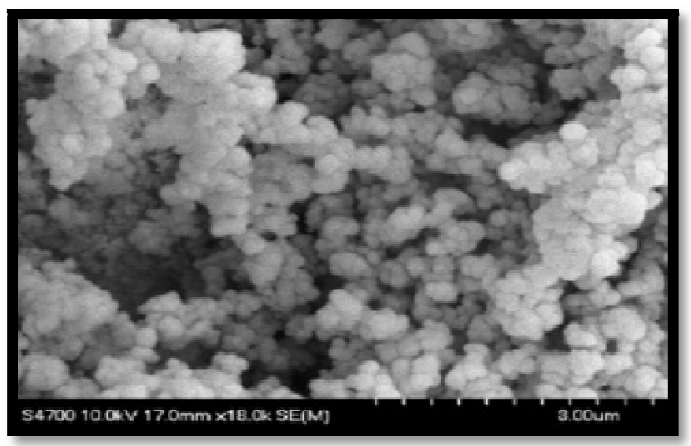

Figure 3: SEM(A)

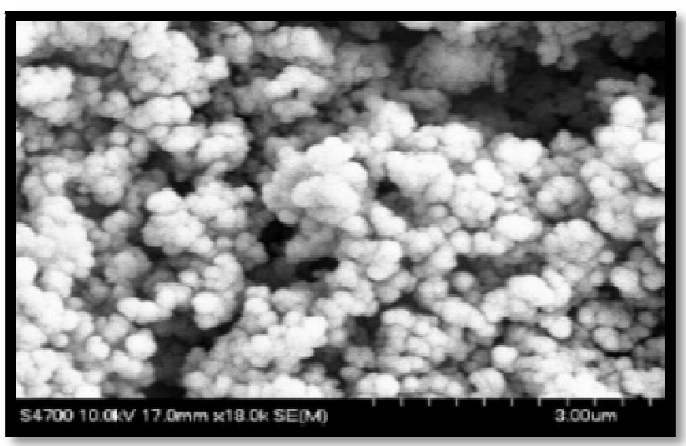

Figure 4: SEM(B)

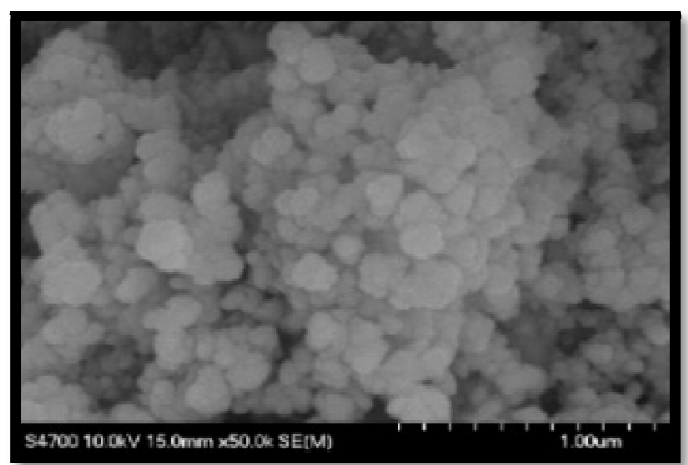

Figure 5: $\operatorname{SEM}(C)$

The crystalline sizes obtained from XRD measurements and SEM estimations, show that from figure 3, 4 and 5, we observe catalyst individual crystals and agglomerates. The particle sizes of catalyst B (169 nm) were bigger compared to the other catalysts, but had the smallest specific surface area $\left(10 \mathrm{~m}^{2} / \mathrm{g}\right)$. Smaller particle sizes were observed in catalyst C $(9 \mathrm{~nm})$ and the largest specific surface area $\left(250 \mathrm{~m}^{2} / \mathrm{g}\right)$. Catalyst A had particles size of $(28 \mathrm{~nm})$ and specific surface area $\left(50 \mathrm{~m}^{2} / \mathrm{g}\right)$. The morphological characterization indicates distinct properties between the three powder catalysts.

\subsection{UV-Vis Spectra of 4-Chlorophenol}

Figure 6 below shows a UV-Vis spectrum for 4 -Chlorophenol c $\left(1 \times 10^{-4} \mathrm{~mol}_{\mathrm{L}} \mathrm{L}^{-1}\right)$ to determine $\lambda_{\text {(max) }}$

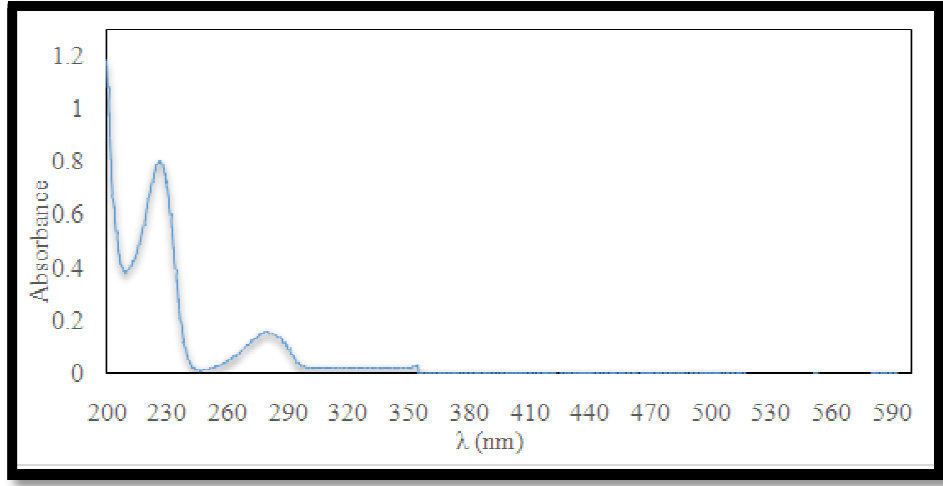

Figure 6: UV-Vis Spectrum of 4-Chlorophenol 
The scan showed a maximum absorption wavelength peaks at $\lambda=(226 \mathrm{~nm}$ and $282 \mathrm{~nm})$ which means 4Chlorophenol absorbs light in the UV region. The photocatalytic degradation experiments in this work was determined at $\lambda=226 \mathrm{~nm}$, which was more pronounced compared to $\lambda=282.5 \mathrm{~nm}$. It implies that 4-Chlorophenol has peak absorbance at 226 and $282 \mathrm{~nm}$. This figure is quite close to $\lambda=227 \mathrm{~nm}$ and $280 \mathrm{~nm}$ reported in literature by (Bustos-Ramírez et al., 2015). Between $\lambda=(300-600 \mathrm{~nm})$. The contaminant in the study 4-Chlorophenol, was noted not to absorb any visible light $(\lambda=390-790 \mathrm{~nm})$ as observed in figure 6 .

\subsection{Calibration curve 4-Chlorophenol (Molar Extinction Coefficient ( $\varepsilon$ ))}

The Molar Extinction Coefficient was determined through a standard calibration curve plotted in Figure 7 below.

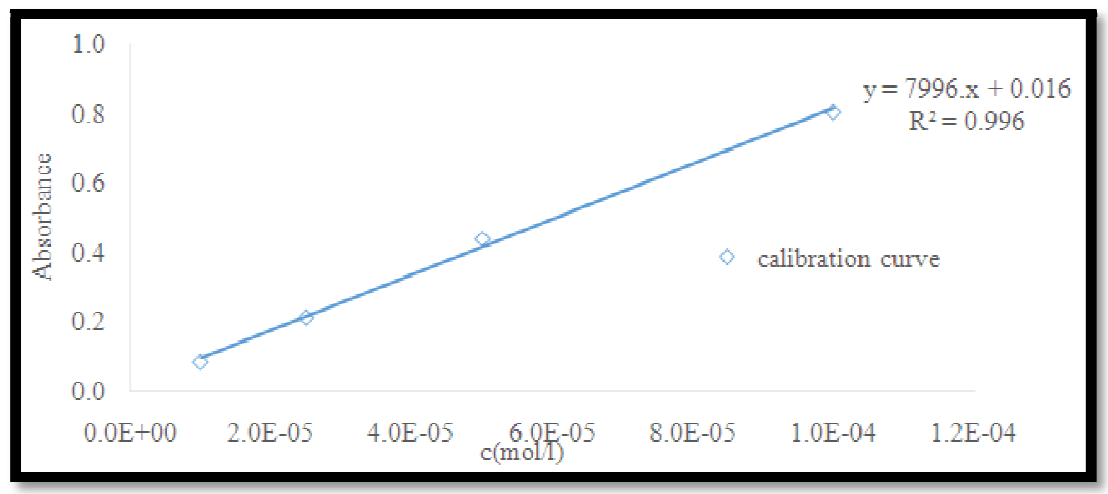

Figure 7: Calibration Curve 4-Chlorophenol

To determine the extinction coefficient $(\varepsilon)$ of 4-Chlorophenol, the following concentrations 4 solutions of various concentrations were prepared from a stock solution of $1 \times 10^{-4} \mathrm{~mol}$. $\mathrm{L}^{-1}$. These were, $\left(1 \times 10^{-5} \mathrm{~mol} . \mathrm{L}^{-1}, 2.5 \times 10^{-5} \mathrm{~mol}^{-\mathrm{L}^{-1}}, 5 \times 10^{-5}\right.$ mol. $\mathrm{L}^{-1}$ and $\left.1 \times 10^{-4} \mathrm{~mol} . \mathrm{L}^{-1}\right)$. A cuvette of $1 \mathrm{~cm}$ unit length and a UV-Vis spectrophotometer, absorbance for these solutions was measured at $\lambda_{\max }=226 \mathrm{~nm}$. By plotting absorbance against concentration, a calibration curves were generated and using the line equation, the molar extinction coefficient $(\varepsilon)$ was determined to be $7996.5 \mathrm{~mol}^{-1} \mathrm{dm}^{3} \mathrm{~cm}^{-1}$.

\subsection{Photocatalytic Degradation of 4 -Chlorophenol}

The removal of 4-Chlorophenol was measured by its rate of its photocatalytic degradation.

This work studied the effect of catalyst annealing temperature, morphology and its subsequent effect on the rate of degradation. The rates of 4-Chlorophenol was studied using catalysts annealed at temperatures between $500-700^{\circ} \mathrm{C}$ and recorded in figure $8,9,10,11 \& 12$. The influence of $\mathrm{TiO}_{2}$ annealing temperatures on the rates of 4-Chlorophenol degradation are discussed in figure 13 and 14.

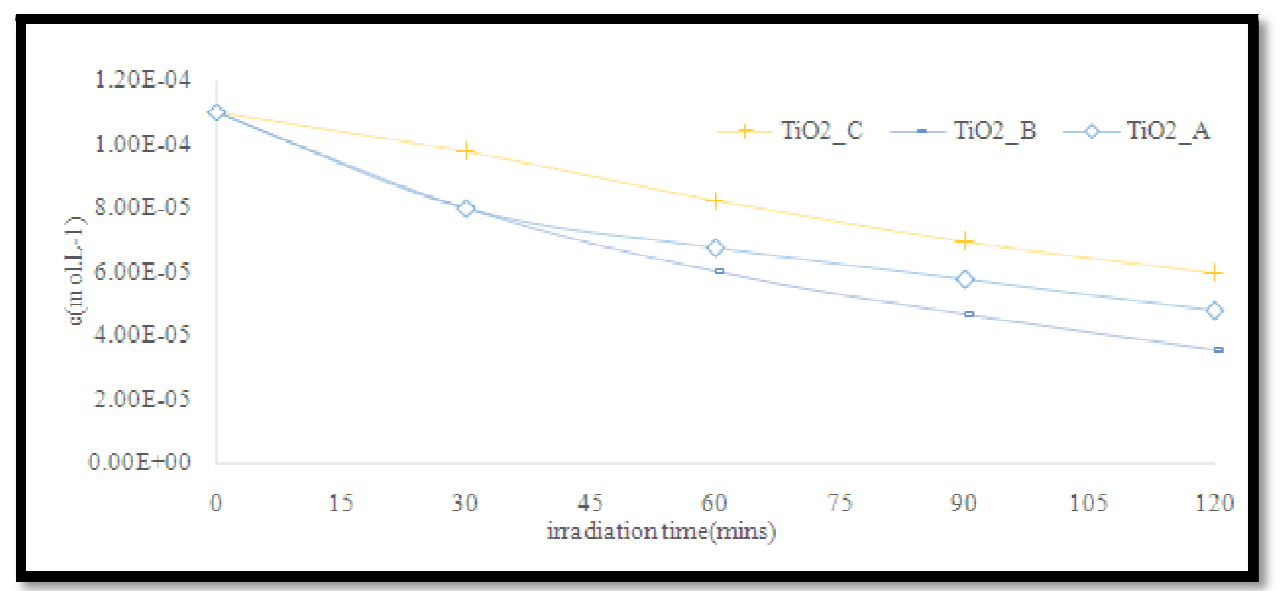

Figure 8: Degradation of 4-Chlorophenol Using Selected $\mathrm{Tio}_{2}$ Catalysts Annealed At $500^{\circ} \mathrm{C}$

\subsubsection{Degradation of 4-Chlorophenol Using Selected $\mathrm{Tio}_{2}$ Commercial Catalysts Annealed at $500^{\circ} \mathrm{C}$}

The results above indicated that at $500^{\circ} \mathrm{C}$, optimum rates of 4-Chlorophenol degradation rates was achieved. The $\mathrm{B}$ catalyst was the most photo catalytically active and $\mathrm{C}$ the least. At this. After 2 hours of $\mathrm{UV}^{-\mathrm{TiO}_{2}}$ photocatalytic degradation system, the removal of 4-Chlorophrnol was measured; B- $68.02 \%$, C-46.25\% and A-56.46\%. This result was influenced by the irregular shape of $\mathrm{TiO}_{2}$ particles at low temperatures causing low kinetic energy that is not sufficient to induce coalescence of the individual $\mathrm{TiO}_{2}$ grains. 


\subsubsection{Degradation of 4-Chlorophenol Using Selected Tio 2 Catalysts Annealed at $550^{\circ} \mathrm{C}$}

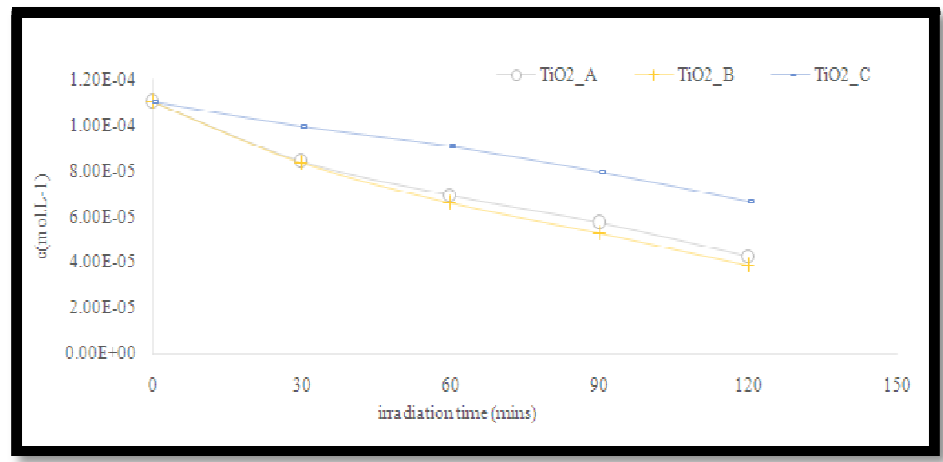

Figure 9: Degradation of 4-Chlorophenol Using Selected Tio 2 Catalysts Calcined at $550^{\circ} \mathrm{C}$.

Figure 9 showing photocatalyst of B decreasing 4-Chlorophenol the fastest with irradiation time compared to A and C. On the other side Photocatalyst $\mathrm{C}$ shows the slowest decrease of the concentrations of 4-Chlorophenol. Changes in 4-Chlorophenol concentration after 2 hours are then used to calculate degradation rates as follows; B-64.85\%, C-39.68\% and $\mathrm{A}-61.11 \%$ ). Compared to $500^{\circ} \mathrm{C}$, the degradation rates were observed to decrease by a collective average $5.08 \%$. The probable cause is the sintering of the immobilized catalysts. The possible explanation can be in the loss of $\mathrm{TiO}_{2}$ particles

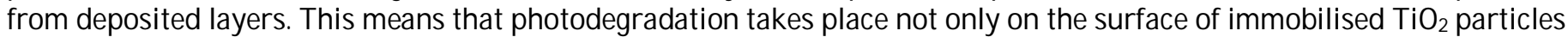
but also on small amount of suspended particles. This is the only probable explanation and will have to be verified in further work.

\subsubsection{Degradation of 4-Chlorophenol Using Selected Tio 2 Catalysts Annealed at $600^{\circ} \mathrm{C}$.}

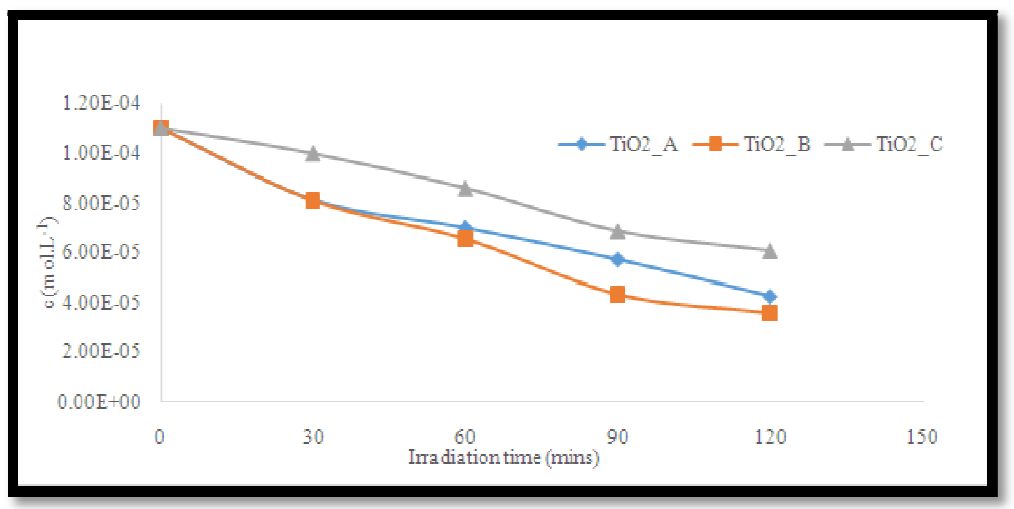

Figure 10: Degradation of 4-Chlorophenol Using Selected $\mathrm{Tio}_{2}$ Catalysts Calcined at $600^{\circ} \mathrm{C}$.

Figure 10 shows that B catalysts degraded 4-Chlorophenol more rapidly compared to A and C. After 2 hours of $\mathrm{UV} / \mathrm{TiO}_{2}$ photocatalytic treatment, the removal of 4-Chlorophenol was determined to be; (B-67.64\%, C-44.78\% and A$61.68 \%$ ). Compared to immobilized layers annealed at $550^{\circ} \mathrm{C}$, the rate of 4-Chlorophenol degradation increased slightly at $600^{\circ} \mathrm{C}$. A possible explanation could be the modification in catalyst morphology as a result of annealing.

\subsubsection{Degradation of 4-Chlorophenol Using Selected Tio 2 Catalysts Annealed at $650^{\circ} \mathrm{C}$}

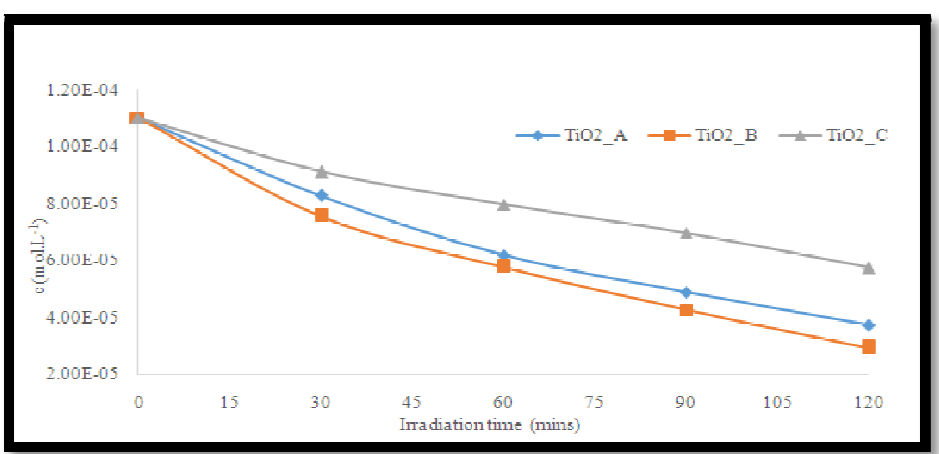

Figure 11: Degradation of 4-Chlorophenol Using Selected Tio 2 Catalysts Annealed at $650^{\circ} \mathrm{C}$. 
Figure 11 indicate the optimum annealing temperature for the degradation of 4-Chlorophenol was determined to be $650^{\circ} \mathrm{C}$. At this calcination temperature, the rates of degradation for 4-Chlorophenol was optimized. Compared to the results shown in figure 8, 9 and 10, B catalyst was most photocatalytically active and C the least. After 2 hours of photocatalytic degradation, the removal of 4-Chlorophenol was measured to be; (B-71.21\%, C-43.80\% and A-63.61\%). At this annealing temperature the $\mathrm{TiO}_{2}$ crystallite structure is suggested to be modified by annealing temperature and subsequently the rate of 4-Chlorophenol removal.

\subsubsection{Degradation of 4-Chlorophenol Using Selected Tio 2 Catalysts Annealed at $700^{\circ} \mathrm{C}$}

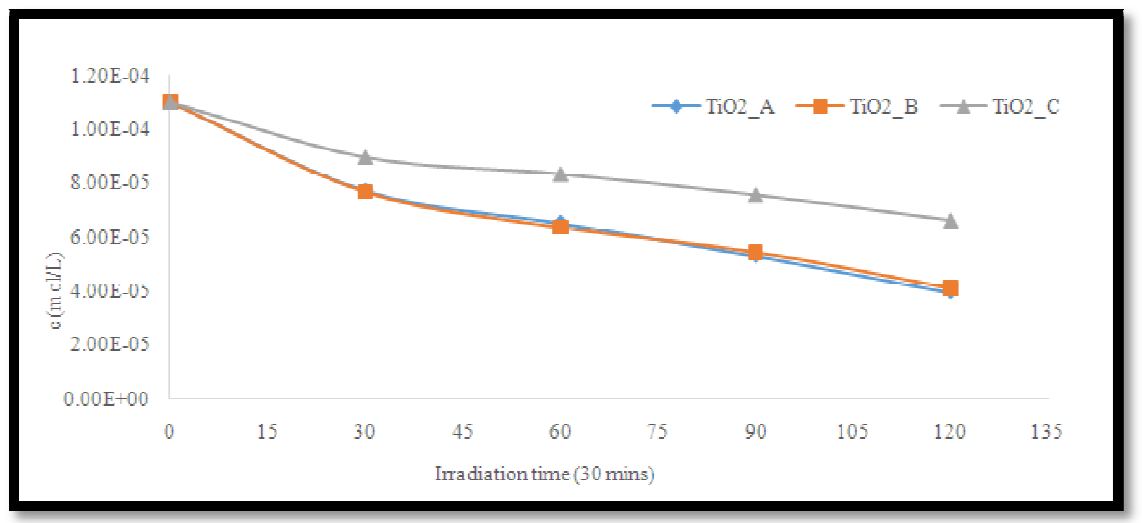

Figure 12: Degradation of 4-Chlorophenol by $\mathrm{Tio}_{2}$ Catalysts Annealed at $700^{\circ} \mathrm{C}$.

From figure 12 as observed from the other annealing temperatures, B catalyst was the most photocatalytically active and $\mathrm{C}$ the least. After 2 hours of photocatalytic degradation, the removal of 4-Chlorophenol was measured at; (B$67.19 \%, \mathrm{C}-35.36 \%$ and $\mathrm{A}-61.36 \%$ ). At $700^{\circ} \mathrm{C}$ most likely the crystal grains in the immobilized films would get larger as a result of densification. The rates of 4 -Chlorophenol removal declined by $12.98 \%$ at temperature interval $650-700{ }^{\circ}$. This means that annealing temperatures above $650^{\circ} \mathrm{C}$ have a negative effect on rate of 4-Chlorophenol degradation due to the morphological $\mathrm{TiO}_{2}$ transformation from anatase to rutile. The rutile phase is less crystalline compared to anatase phase leading to decreased rates of 4-Chlorophenol.

\subsubsection{Photocatalytic Degradation of 4-Chlorophenol C $\left(1 \times 10^{-4} \mathrm{M}\right)$ Using Tio 2 Catalysts Annealed at Temperatures between} $\underline{500-700^{\circ} \mathrm{C}}$

Figure 13 below analyses the correlation between the rates of 4-Chlorophenol degradation, the type of $\mathrm{TiO}_{2}$ catalyst and annealing temperatures 500-700年.

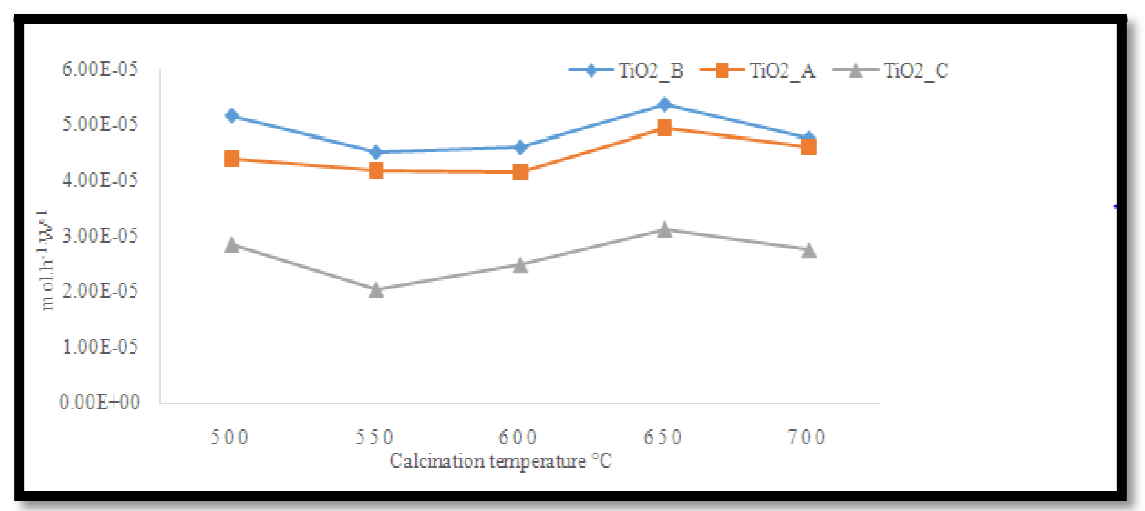

Figure 13: Effect of $\mathrm{Tio}_{2}$ Catalyst Calcination Temperature on the Rate of 4Chlorophenol Removal after 1 Hour of Photocatalytic Treatment

An increase in calcination temperatures in the range $500-550^{\circ} \mathrm{C}$ had an average negative effect. $5.08 \%$ on the degradation rate of 4-Chlorophenol which can be explained by sintering of catalyst particles that causes it to bind and fuse together causing the particles to grow and form agglomerates. A significant increase $12.98 \%$ in 4-Chlorophenol degradation was observed at calcination temperatures between $550-650^{\circ} \mathrm{C}$. Between $650-700^{\circ} \mathrm{C}$ the degradation rates of 4Chlorophenol decreased by $14.71 \%$ due to morphological Phase transformation from anatase to rutile phase at $700^{\circ} \mathrm{C}$ annealing temperature. The results show that $650^{\circ} \mathrm{C}$ is optimum calcination temperature to achieve effective degradation of 4-Chlorophenol, the findings show that the following levels of efficiency in removing 4-Chlorophenol was achieved at $650^{\circ} \mathrm{C}$; (A-63.61\%, C-43.80\% and B-71.21\%). The findings in figure 13, corroborate the results obtained in figure 8, 9, 10, $11 \& 12$ that indicate similar trends. The shifting rates of 4-Chlorophenol removal with increased annealing temperatures can be explained as follows; the most influential parameter would be the decrease in the density of structural defects, whereas the decrease in surface area would have a lesser influence in the removal of 4-Chlorophenol. This is caused by the 
poor adsorption properties of 4-Chlorophenol and density of defects with regards to catalyst surface area for most aromatic contaminants such as 4-Chlorophenol. This means photocatalytic reactions react in the vicinity of $\mathrm{TiO}_{2}$ and not on its surface. The higher specific surface area of $\mathrm{C}$ does not positively affect the rates of 4-Chlorophenol degradation because it does not presumably react principally at the surface.

\subsubsection{Effect of $\mathrm{TiO}_{2}$ Calcination Temperature on the Concentration of 4-Chlorophenol} $700^{\circ} \mathrm{C}$. Figure 14 shows change in 4-Chlorophenol concentration with increasing calcination temperature between 500-

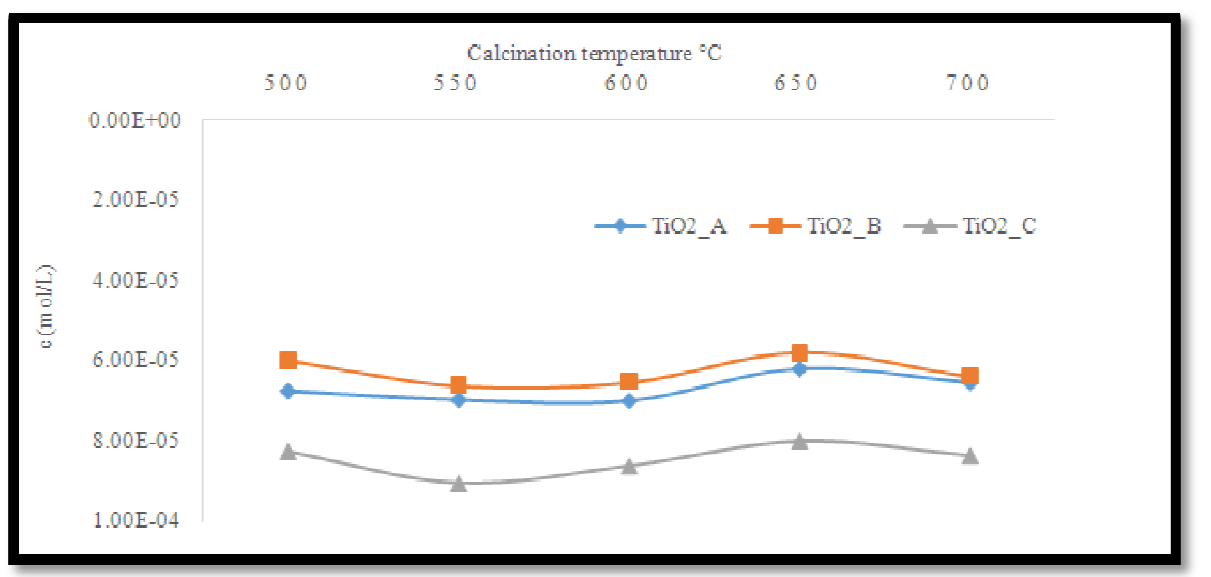

Figure 14: Changes in 4-Chlorophenol Concentration with Selected Tio 2 Catalyst after $1 \mathrm{Hr}$. of Photocatalytic Degradation

The results in figure 14 are similar to the findings obtained in figure 13. Figure 14 shows the correlation between fluctuations in 4-Chlorophenol $\mathrm{c}\left(\mathrm{mol}_{\mathrm{L}} \mathrm{L}^{-1}\right), \mathrm{TiO}_{2}$ catalyst and annealing temperature. Furthermore, the findings corroborate the results shown in figure 8, 9,10,11,12 \& 13 .

Annealing of $\mathrm{TiO}_{2}$ catalysts remove defects on the crystalline planes, thereby reducing $\mathrm{TiO}_{2}$ internal stresses and improving ductility of metallic alloys as observed between annealing temperatures $550-650^{\circ} \mathrm{C}$.The reduction in the rates of 4-Chlorophenol above $650^{\circ} \mathrm{C}$ was caused by morphological transformations from anatase to rutile phase, thus decreasing $\mathrm{TiO}_{2}$ crystallinity and photocatalytic activity.

\section{Conclusions}

The present study established a high photocatalytic activity of $\mathrm{TiO}_{2}$ for the degradation of 4-Chlorophenol under UV light irradiation. B catalyst showed the highest photocatalytic activity for degradation of 4-Chlorophenol and C the least photoactivity. Annealing had a significant influence on the resultant photocatalytic activity of the produced immobilized layers. Annealing temperatures above $650^{\circ} \mathrm{C}$ negatively affect rates of 4-Chlorophenol degradation However, higher annealing temperatures of $\mathrm{TiO}_{2}$ weights more for the removal of the 4-Chlorophenols from wastewater. Significantly, the optimum annealing temperature was determined to be $650^{\circ} \mathrm{C}$. The results show that increases $\mathrm{TiO}_{2}$ crystal size favoured higher rates of 4-Chlorophenol removal, while catalyst surface area had little effect, however powder catalyst surface area has little effect on 4-Chlorophenol degradation. In the present study, no correlation between specific surface area and rate of 4-chlorophenol removal was established. The surface morphology of $\mathrm{TiO}_{2}$ immobilized layers was influenced by annealing temperature.

\section{Acknowledgements}

The authors thank the Department of Inorganic technology, University of Chemistry and Chemical Technology, Prague - Czech Republic for use of Laboratory space and analytical facilities.

\section{References}

i. Bustos-Ramírez, K., Barrera-Díaz, C.E., De Icaza-Herrera, M., Martínez-Hernández, A.L., Natividad-Rangel, R \& Velasco-Santos, C. (2015). 4-chlorophenol removal from water using graphite and graphene oxides as photocatalysts, Journal of Environmental Health Science \& Engineering. 13 (33);

ii. Kuo, W.S \& Lin, I.T. (2009). Biodegradability of chlorophenol wastewater enhanced by solar photo-Fenton process. Water Sci Technol, 59 (5): 973-978.

iii. Westmeier, F \& Rehm, H.J. (1987). Degradation of 4-chlorophenol in municipal wastewater by adsorptive immobilized Alcaligenes sp. A 7-2. Applied Microbiology and Biotechnology. Volume 26, issue 1, pp.78-83.

iv. Seo, J.K., Ki-Joon, J., Young-Kwon, P., Sangmin, J., Heon, L \& Sang-Chul, J. (2017). Improving removal of 4chlorophenol using a $\mathrm{TiO}_{2}$ photocatalytic system with microwave and ultraviolet tradition. Catalysis Today. Vol. 293-294. pp.15-22.

v. Catrinescu, C., Arsene, D and Teodosiu, C. (2011). Catalytic wet hydrogen peroxide oxidation of para-chlorophenol over Al/ Fe pillared clays (AlFePILCs) prepared from different host clays. Appl Catal Environ., 101, 451-460. 
vi. Assadi, A and Eslami, A. (2010). Comparison of phenol photodegradation by $\mathrm{UV} / \mathrm{H}_{2} \mathrm{O}_{2}$ and photo-Fenton processe. Environ Eng Manag J., 9: 807-812.

vii. Gaya, U.I., Abdullah, A.H., Zainal, Z and Hussein, M.Z. (2009). Photocatalytic treatment of 4-chlorophenol in aqueous $\mathrm{ZnO}$ suspensions: Intermediates, influence of dosage and inorganic anions.J Hazard Mater., 168: 57-63.

viii. Han, D.H., Cha, S.Y and Yang, H.Y. (2004) Improvement of oxidative decomposition of aqueous phenol by microwave irradiation in $\mathrm{UV} / \mathrm{H}_{2} \mathrm{O}_{2}$ process and kinetic study. Water Res., 38, pp. 2782-2790.

ix. $\quad$ Barnes, R.J., Riba, O., Gardner, M.N., Scott, T.B., Jackman, S.A and Thompson, I.P. (2010). Optimization of nano-scale nickel/iron particles for the reduction of high concentration chlorinated aliphatic hydrocarbon solutions. Chemosphere, 79, 448-454.

x. Eslami, A., Nasseri, S., Yadollahi, B., Mesdaghinia, A., Vaezi, F and Nabizadeh, R. (2007) Application of photocatalytic process for removal of methyl tert-butyl ether from highly contaminated water. Iran J Environ Health Sci Eng., 4,215-222.

xi. Lo, S.C., Lin, C.F., Wu, C.H., Hsieh, P.H. (2004). Capability of coupled CdSe/ $\mathrm{TiO}_{2}$ for photocatalytic degradation of 4chlorophenol. J Hazard Mater., 114, 183-190.

xii. Ghosh, J.P., Sui, R., Langford, C.H., Achari, G., Berlinguette, C.P. (2009). A comparison of several nanoscale photocatalysts in the degradation of a common pollutant using LEDs and conventional UV light. Water Res., 43, 4499-4506.

xiii. Gimeno, O., Carbajo, M., Beltrán, F.J., Rivas, F.J. (2004). Phenol and substituted phenols AOPs remediation. J Hazard Mater., 119, 99-108.

xiv. Li, J. M., Meng, X.G., Hu, C.W., Du, J and Zeng, X.C. (2008). Oxidation of 4-chlorophenol catalyzed by Cu (II) complexes under mild conditions: Kinetics and mechanism.J Mol Catal A Chem., 299: 102-107.

xv. Lai, T.L., Liu, J.Y., Yong, K.F, Shu, Y.Y., Wang, C.B. (2008). Microwave-enhanced catalytic degradation of 4chlorophenol over nickel oxides under low temperature.J Hazard Mater., 157, 496-502.

xvi. Stoyanova, M and Christoskova, S. (2011). Catalytic degradation of methylene blue in aqueous solutions over Niand Co- oxide systems. Cent Eur J Chem., 9, 1000-1007.

xvii. Stoyanova, M., Christoskova, S and Georgieva, M. (2003). Mixed Ni-Mn-oxide systems as catalysts for complete oxidation: Part I. Preparation and characterization. Appl Catal A Gen., 249, 285-294.

xviii. Movahedyan, H., Assadi, A and Amin, M.M. (2008). Effects of 4-chlorophenol loadings on acclimation of biomass with optimized fixed time sequencing batch reactor. Iran J Environ Health Sci Eng., 5, 225-234.

xix. Movahedyan, H.S., Mohammadi, A.M and Assadi, A. (2009). Comparison of Different Advanced Oxidation Processes Degrading P-Chlorophenol In Aqueous Solution. Iran J Environ Health Sci Eng., 6, 153-160.

xx. Gomez, M., Matafonova, G., Gomez, J.L, Batoev, V and Christofi, N. (2009). Comparison of alternative treatments for 4-chlorophenol removal from aqueous solutions: Use of free and immobilized soybean peroxidase and $\mathrm{KrCl}$ excilamp. J Hazard Mater., 169, 46-51.

xxi. Olaniran, A.O and Igbinosa, E.O. (2011). Chlorophenols and other related derivatives of environmental concern: Properties, distribution and microbial degradation processes. Chemosphere., 83, 1297-1306.

xxii. $\quad$ Pera-Titus, M., García-Molina, V., Baños, M.A., Giménez, J and Esplugas, S. (2003). Degradation of chlorophenols by means of advanced oxidation processes: a general review. Appl Catal Environ,. 47, 219-256.

xxiii. Pi, Y., Zhang, L and Wang, J. (2007). The formation and influence of hydrogen peroxide during ozonation of parachlorophenol.J Hazard Mater., 141, 707-712.

xxiv. Krýsa, J., Waldner, G., Měšt'ánková, H., Jirkovský, J and Grabner, G. (2006). Photocatalytic degradation of model organic pollutants on an immobilized particulate $\mathrm{TiO}_{2}$ layer: Roles of adsorption processes and mechanistic complexity. Appl Catal Environ., 64, 290-301.

xxv. Marianna, C. (2005). Photo-degradation of chlorophenols in the aqueous solution.J Hazard Mater., 134, 45-59.

xxvi. Lin, C-F, Wu, C-H and Onn, Z-N. (2008). Degradation of 4-chlorophenol in $\mathrm{TiO}_{2}, \mathrm{WO}_{3}, \mathrm{SnO}_{2}, \mathrm{TiO}_{2} / \mathrm{WO}_{3}$ and $\mathrm{TiO}_{2} / \mathrm{SnO}_{2}$ systems. J Hazard Mater., 154, 1033-1039.

xxvii. Ghaly, M.Y, Härtel, G., Mayer, R and Haseneder, R. (2001). Photochemical oxidation of p-chlorophenol by UV/ $\mathrm{H}_{2} \mathrm{O}_{2}$ and photo-Fenton process. A comparative study. Waste Manag., 21, 41-47.

xxviii. Lai, T-L., Wang, W-F., Shu, Y-Y., Liu, Y-T and Wang, C-B. (2007). Evaluation of microwave-enhanced catalytic degradation of 4-chlorophenol over nickel oxides. J. Mol Catal A Chem., 273, 303-309.

xxix. Chiou, C-H., Wu, C-Y and Juang, R-S. (2008). Influence of operating parameters on photocatalytic degradation of phenol in $\mathrm{UV} / \mathrm{TiO}_{2}$ process. Chem EngJ., 139, 322-329.

xxx. Dixit, A., Mungray, A.K and Chakraborty, M. (2010). Photochemical Oxidation of Phenol and Chlorophenol by UV/ $\mathrm{H}_{2} \mathrm{O}_{2} / \mathrm{TiO}_{2}$ Process: A Kinetic Study. Int J Chem Eng Appl., 1. 247-250.

xxxi. Tabatabaei, S.M., Dastmalchi, S., Mehrizad, A and Gharbani, P. (2011). Enhancement of 4-nitrophenol ozonation in water by nano ZnO catalyst. Iran J Environ Health Sci Eng., 8, 363-372.

xxxii. Gimeno, O., Carbajo, M., Beltrán, F.J and Rivas, F.J. (2005). Phenol and substituted phenols AOPs remediation. J Hazard Mater., 119, 99-108.

xxxiii. Ajmal, A., Majeed, I., Malik, R. N., Idriss, H., \& Nadeem, M. A. (2014). Principles and mechanisms of photocatalytic dye degradation on $\mathrm{TiO}_{2}$ based photocatalysts: A comparative overview. Rsc Advances, 4, (70), 37003-37026.

xxxiv. Carp, O., Huisman, C. L and Reller, A. (2004). Photoinduced reactivity of titanium dioxide. Progress in solid state chemistry, 32(1), 33-177. 